\title{
Marketing Yourself as a Clinical Nurse Leader
}

Janice Wilcox

"Your value doesn't decrease based on someone's inability to see your worth; enlighten them anyway!"

Unknown

\section{INTRODUCTION}

The clinical nurse leader (CNL) nursing specialty was developed to address deficiencies and gaps in care related to quality and safety within our healthcare systems. The American Association of Colleges of Nursing (AACN; 2018a) defines the CNL as follows:

A master's educated nurse, prepared for practice across the continuum of care within any healthcare setting in today's changing healthcare environment. CNLs oversee care coordination, provide direct patient care in complex situations, put evidence-based practice into action, ensure patients benefit from the latest innovations in care delivery, evaluate patient outcomes and assess cohort risk and have the decisionmaking authority to change care plans when necessary. The $C N L$ is a leader and active member of the interdisciplinary

Copyright Springer Publishing Company. All Rights Reserved.

From: Fast Facts for the Clinical Nurse Leader 
healthcare team. The implementation of the CNL role will vary across health care settings. (para. 6)

You most likely learned in your educational programs that leaders from education and practice came together to envision and initiate this new nursing role to enhance safety and improve outcomes through lateral integration of care. This lateral integration of care improves communication and practice among interprofessional teams. You have learned how to manage teams, improve processes, and initiate and sustain change through the use of evidence-based practices and the use of quality improvement tools. Your education also provided you with knowledge and skills to move care to higher standards, and you are ready to reach your goals to create change. However, obtaining your dream position may take a little work. The CNL role is relatively new, and not every organization has adopted it within its care models; therefore, marketing yourself is of great importance. This chapter provides you with tips and tools to market yourself as a CNL, obtain your dream position, and also change healthcare for the better.

\section{After reading this chapter, you will be able to:}

1. Identify strategies to guide you in creating or obtaining a CNL position

2. Recognize important steps in preparing an impactful presentation

3. Differentiate your role from other nursing leaders' roles

4. Understand the importance of maintaining a portfolio

5. Utilize available career resources

\section{RATIONALE FOR THE CNL POSITION}

When thinking about how to go about obtaining a CNL position, it is good to review and keep in mind why this first new nursing role in over 30 years was developed. A review of the facts will act as a refresher to ultimately help in marketing yourself. You probably recall the Institute of Medicine's (IOM) landmark reports from 1999 and 2000. These reports highlighted concerns within our healthcare system related to errors and gaps in care contributing to thousands of deaths per year from medical errors and safety issues. They also reported on inefficient practices with poor utilization of resources 
that contributed to less-than-desirable outcomes and rising healthcare costs (IOM, 1999, 2000).

This information initiated discussions regarding nursing's role in dealing with these issues. It was determined that nurses were key players in improving care and care outcomes due to their direct relationship with patients, family, and providers of care. Nurses are responsible for the development, implementation, and evaluation of care; therefore, their insight and input is invaluable in improving care. However, it was also determined that a different nurse was needed, one with a higher level of education, who would not only be the clinical expert but also be the leader at the point of care who understands systems and processes that impact care. The AACN, healthcare leaders, and educators used the information and foresight in developing the new nursing role, or the CNL (AACN, 2007).

Unfortunately, the overall healthcare system has not seen improvements in care and outcomes since the original reports were published. Sternberg (2016) reported that medical errors are now the third leading cause of death with 250,000 deaths per year, and Makary and Daniel (2016) wrote in the BMJ that the estimated deaths caused from medical errors in the United States to be anywhere from 200,000 to 400,000 per year. These numbers only emphasize the need for greater numbers of CNLs within healthcare organizations and will help you in marketing yourself as a CNL.

Since the initiation of the role in 2005, approximately 5,000 nurses have earned the CNL certification (Commission on Nurse Certification [CNC], 2017). Evidence is mounting on the benefits that CNLs bring to organizations. Some of the benefits seen from these nurses include decreasing readmission rates, improving incidences of patient falls and hospital-acquired infections, improving patient satisfaction scores, reducing canceled procedures, and improving nurse turnover rates (Bender, 2014; Hix, McKeon, \& Walters, 2009; Moore, 2013; Sotomayor \& Rankin, 2017). This is just a sampling of the benefits to organizations that you can use as starting points to develop your marketing campaign to acquire your dream position.

\section{WHERE ARE CNLS EMPLOYED}

According to the CNC (2017), data gathered from polling of current CNLs indicate the majority of CNLs work in urban acute care settings. Many organizations throughout the United States are adopting the CNL role within their microsystems with positive results. For example, the Veterans Administration (VA) was one of the first adopters of this role and continues to expand the CNL role within its organizations (U.S. Department of Veterans Affairs, n.d.). WellStar 
Health System also employs many CNLs with similar results as the VA (Case-Wirth, 2018). Organizational adoption of the CNL role is expanding throughout the country with many other organizations initiating this role, but like any change process, advancement is slow.

There are other areas of nursing where you can utilize your education and skills. These include schools of nursing, where CNLs can apply their knowledge and clinical expert skills as clinical faculty teaching nursing students. Outpatient clinics, physician's practices, and home healthcare suit the CNL skill set in the way of care coordination and outcomes manager assisting the navigation of patients throughout different healthcare settings. Public health departments employ CNLs in focusing on population-wide efforts to reduce disparities in care or improve access to care of at-risk populations. Rankin, Ralyea, and Sotomayor (2017) discuss how the CNLs employed within a certain medical center collaboratively work with high-risk obstetric patients in both the acute and community settings. CNLs in both outpatient and inpatient units work collaboratively to meet the needs of these patients, ensuring they receive the screenings and care that will prevent further admissions and complications of pregnancy. CNLs can also be found working in staff development and case management positions, so your options for employment are many. As an advanced generalist, the CNL has the knowledge and skills to impact many different areas of patient care.

\section{Initiating the Role}

At times, a nurse may wish to work within an organization that does not employ CNLs as the role was envisioned, or the particular unit does not have a CNL position within the care team. This may require effort to initiate the role. Many CNLs have gained their positions from advocating for the role and themselves. Having discussions with nurse managers, nurse educators, or nursing supervisors is a good way to launch this endeavor. Make sure to meet with persons when they have time to discuss ideas and when they are not distracted with other concerns; timing can be a critical factor in presenting new initiatives. Arrange a set appointment time to meet, and then organize your thoughts and ideas to ensure you are able to get your points across in that set amount of time. Begin by discussing issues that are occurring within the unit, and explain how a certified CNL can address these issues. Keep in mind the previous information regarding the rationale for the CNL role. Healthcare leaders are absorbed with the task of improving care outcomes and quality; therefore, it is best to focus on how improvements can be achieved in any of these areas. 


\section{Fast Facts}

Advocating for the initiation of your CNL role within a particular setting is critical. Presenting decision-makers with a clear picture of what you have done and/or can do clinically and financially for their organization is key!

\section{MAKING YOUR CASE}

In preparing the proposal, it is very important to also prepare the manner in which it will be delivered. Studies in neuroscience and communication are discovering that many brain processes are involved with decision-making, especially financial decision-making, and ultimately, initiation of a CNL position will impact organizations financially (Lahmiri, 2016). Your goal is to persuade others to believe that the CNL role will positively impact the unit and the organization by demonstrating the value. At the same time, from the moment you begin speaking, you are attempting to motivate and instill passion for change in those who are listening. This means you must create a sense of urgency without instilling a sense of danger. In neuroscience language, you must reach the neocortex of the brain, and to get to the neocortex, you must pass through the amygdala. Ousdal et al. (2014) state that the brain's amygdala works to avoid unpleasant or harmful events. Therefore, if the receiving message is too boring, is uninspiring, or creates a sense of threat, the amygdala (which is the flight or fight area of the brain) will inhibit the message from getting to the neocortex where the person can process it.

\section{The "Why"}

Sinek $(2009,2014)$ uses neuroscience philosophies in describing how to motivate and inspire when communicating by stating the "why" or your purpose or your mission prior to describing the "how" and "what" of your proposal. To determine your "why," begin with the current outcomes within the microsystem that you want to address. What are the metrics indicating in the way of quality and safety outcomes, such as falls, central line and urinary catheter infections, and pressure ulcers? What are the patient and staff satisfaction rates? What effects are the metrics having within your organization financially? These metrics will give you the "why" of your proposal. 
For example, your nurse engagement rates are declining, and your unit is seeing an increase in nurse burnout and higher turnover rates. Falls rates have increased from three to seven in the past quarter, which may be contributing to the poor patient satisfaction scores and higher costs due to unreimbursed injury. These metrics will give you the "why" of your proposal. Your "why" message to the leaders may be something like "Our mission is to improve the health of those we serve and the unit is seeing an increase in falls in the last two quarters which is contributing to less than desirable patient and financial outcomes. There is also a problem with nurse engagement as the nurse turnover rate has increased dramatically over the last year. These factors are contributing to poor patient outcomes, increased financial loss for the unit and not contributing to our mission. A CNL can improve nurse retention by being a resource and mentor for newer staff members, coordinate and oversee care to address why patients are falling, and ensure the processes are in place to maintain safety efforts in decreasing falls, which will ultimately improve patient and financial unit outcomes" (Sinek 2014). In describing your cause in this manner, you are able to create a sense of urgency or a "need" that these issues must be addressed promptly, without losing the attention of those who are listening. Viewing Sinek's (2014) YouTube video may provide insight into creating a talk that will achieve the results you desire.

\section{The "How"}

Your "how" is actually how you are going to improve the problems on your unit. When explaining how you are going to improve processes, you may want to bring in the roles of the CNL. Managers and administrators do not always understand the CNL; therefore, you may need to explain how the role improves care and processes. Use your knowledge of evidence-based practice to demonstrate the value of the CNL. Obtain literature that compares CNL outcomes on similar units. As an example, Ott et al. (2009) discuss the value of the $\mathrm{CNL}$ to the VA in reducing readmissions of heart failure patients. A CNL wishing to work on an inpatient heart failure unit can use this evidence to back the claims of the benefits that the role will bring to the unit.

It may be helpful to gather several pieces of literature to back your claims, and it is not always necessary to have the evidence from your particular specialty area, but it may be helpful as long as you have evidence of success. Highlight the evidence and illustrate the value that you will bring by outlining what you will do to achieve the outcomes. Following are examples based on each CNL role; however, you will 
want to combine this information into a concise illustration of how you will go about improving care and processes as you may not have time to address each of these roles individually in your presentation. Consider the timeframe you will have, and prepare your talk to highlight the most relevant points to your particular situation. Refer to Table 1.1 for a complete list of the different AACN CNL roles.

In addressing the common battle of patient adherence to treatment plans and readmissions, which contribute to declining patient conditions and financial losses for the organization, the CNL may choose to describe their contributions as follows:

- Clinician: Using expertise in the area of heart failure and knowledge of the best evidence in caring for heart failure patients, the CNL provides and evaluates care to ensure positive outcomes by rounding daily on patients; recognizes changes in conditions that require immediate attention; communicates promptly to the interprofessional team ensuring timely interventions; acts as a staff resource in planning and coordinating care, which is patient centered including family and community.

- Outcomes manager: Shares outcomes of care with interprofessional teams to strategize ways of improving care; implements attainable patient discharge goals and maintains contact with the patient/family post discharge to identify early changes in condition and prevention of hospital readmissions; alerts care team of changes in order to address patient changes in condition promptly.

- Client advocate: Acts as a communication conduit between the patient and the interprofessional team while empowering the patient to be a voice in their treatment plan; provides explanations and answers to the patient/family on different types of therapies, treatments, procedures, and medications; confers with social workers and case managers to ensure available financial resources for treatments and medications.

- Educator: Educates patients and families on the stages, signs, and symptoms of heart failure to ensure understanding of what to expect and when to call providers; reviews medications and the importance of adhering to medication schedules and revises schedules to meet the individual patient needs; creates a stepby-step daily plan for each patient based upon their particular individual needs.

- Information manager: Reviews documentation to ensure provision of care is complete and that documentation reflects what actually occurred; relays information to staff regarding latest heart failure treatments and technologies; measures and critiques 
Table 1.1

\section{American Association of Colleges of Nursing (AACN) Clinical} Nurse Leader Roles

Clinician

Outcomes manager

Client advocate

Educator

Information manager

Systems analyst/risk anticipator

Team manager

Member of a profession

Lifelong learner
Designer/coordinator/integrator/evaluator of care to individuals, families, groups, communities, and populations; able to understand the rationale for care and competently deliver this care to an increasingly complex and diverse population in multiple environments. The CNL provides care at the point of care to individuals across the life span with particular emphasis on health promotion and risk reduction services.

Synthesizes data, information, and knowledge to evaluate and achieve optimal client outcomes.

Adept at ensuring that clients, families, and communities are well informed and included in care planning and is an informed leader for improving care. The CNL also serves as an advocate for the profession and the interdisciplinary healthcare team.

Uses appropriate teaching principles and strategies as well as current information, materials, and technologies to teach clients, groups, and other healthcare professionals under their supervision.

Able to use information systems and technology that put knowledge at the point of care to improve healthcare outcomes.

Able to participate in systems review to improve quality of client care delivery and at the individual level to critically evaluate and anticipate risks to client safety with the aim of preventing medical error.

Able to properly delegate and manage the nursing team resources (human and fiscal) and serve as a leader and partner in the interdisciplinary healthcare team.

Accountable for the ongoing acquisition of knowledge and skills to effect change in healthcare practice and outcomes and in the profession.

Recognizes the need for and actively pursues new knowledge and skills as one's role and needs of the healthcare system evolve.

Source: American Association of Colleges of Nursing. (2007). White paper on the education and role of the clinical nurse leader (p. 13). Washington, DC: Author. 
patient outcome data to evaluate processes and procedures; communicates trends to administration and care team.

- Systems analyst/risk anticipator: Works with management when near misses/errors occur to determine cause and provide educational learning opportunities to the care team; analyzes outcomes and explores ways of improving processes; assesses daily patient risks for infection, pressure ulcers, pneumonia, and other nurse-driven indicators and takes steps to decrease risks; analyzes workflows to ensure smooth transition of care.

- Team manager: Coordinates and manages the interdisciplinary team; works with the entire team to confirm the overall plan of care focusing on individual patient needs; communicates all plans in a clear and detailed manner to the patient/family and team; collaborates with nurse manager to present patient/staff reports to administration.

- Lifelong learner: Maintains competence through continuing education in the area of heart failure and encourages staff to further their education by role modeling desire to learn; continuously searches for the most recent evidence and guidelines to manage heart failure patients.

\section{The "What"}

Basically, the "what" of your proposal is the development of the CNL position within the organization or unit. You have stated what the problem is and what you can do about it, and now you need to state that the CNL is the person/role that can address these issues and improve care and processes.

Go on to state that you are the best CNL to do this. You have gained the knowledge and skills from your CNL educational program to identify gaps in processes, initiate change, lead teams, and improve communication practices. You have the expertise in cardiac care to understand the physiologic condition, treatments, and patient characteristics of this population. The organization needs to hire you as the CNL to address the unit process concerns that are affecting care, retention of nurses, and ultimately the financial status of the unit.

If you get buy-in from the manager or other nurse leader, they can be your ally and guide you through your next steps. Remember, though, any organizational change requires time and work. You most likely will be required to develop a formal proposal. This proposal may include costs of the position, reporting structure, duties and responsibilities, organizational expectations, determining your effects on outcomes, and the return on investment for the organization. 
If at first you do not get that positive response, do not give up! Reflect on your message and the manner in which you presented it to determine if you are really getting your point across and are highlighting factors most important to the administrators. Find a mentor-a leader who demonstrates qualities you admire. Meet with them and discuss how they are able to get their points across and create change. They may also be able to provide you with valuable insight into the culture of the organization and what the driving forces are at the moment that you can address in further discussions. Do not be afraid of failing-persistence will pay off in the end if you have the passion and drive to improve the healthcare systems.

\section{Clinical Nurse Leader Vignette 1.1: Creating the Need for the Clinical Nurse Leader}

I remember boldly discussing the CNL role with my boss and the CNO of my hospital prior to my graduation and certification. I wanted them to see my passion for the CNL role and how it could greatly affect patient care and staff satisfaction within my facility and especially within the ICU. They said, "Come and see us when you are all done with school; then we'll talk." I felt dejected and defeated, as though I had given a poor explanation of the role and how it could benefit my hospital, yet I had used all of the right buzzwords, like how I planned to "laterally integrate patient care," explained what an "advanced generalist" was, and discussed how I could be an "advocate for both patients and the healthcare team." What had I done wrong? Will I have to leave this facility before I can perform the role I had worked so hard to learn? How could I convince them CNLs were desperately needed in my facility?

Three months later, about a week before graduation and after I passed the CNL certification exam, I scheduled a meeting with those same two individuals. I reflected upon the positives of the earlier discussion and realized my reaction was the problem, not their comments. They could have easily said a swift "No!" when talking about CNL role implementation, but they did not. In fact, they left the door wide open for me to prove my worth as a CNL. And "worth" is the key word here. How much was it worth to them and the facility to have me perform this new role? I knew exactly what I had to do; show them what I had already done 
for the facility as a CNL student, what I could do for the ICU as a CNL employee, and how all of these activities equated to saving the facility money. There. I said it. Money. No more altruistic discussions about the touchy-feely side of nursing, but the hard, cold facts of 21st-century American healthcare wrapped within a portfolio showcasing the nine CNL roles. I started my new ICU CNL job a month later.

\section{DIFFERENTIATING YOUR ROLE FROM OTHER NURSING ROLES}

Since the CNL is relatively new and not everyone is familiar with what you will bring to the table and how you are different from the other nursing roles within organizations, you may need to articulate the differences. You will need to describe how collaboratively each role works toward the betterment of the organization and care of the patients. Administrators do not always understand the fact that managers, educators, nurse practitioners, and clinical nurse specialists are not always at the point-of-care assisting nurses with their daily routines and overseeing care of the patient or how the point-of-care expert adds great value to the team. CNLs must be able to articulate these differences in order for administration to see that the CNL is a different position tending to different issues within the unit. Table 1.2 provides a brief overview of the various roles and their responsibilities.

\section{Table 1.2}

Differences Between Professional Nursing Roles and the Role of the Clinical Nurse Leader

Role

Clinical Nurse Leader

Manager

- Concentrates on budgets and overall business operations of the unit

- Basic knowledge and understanding of microsystem finances

- Hiring and disciplinary actions of staff

- Manages resources

- Not always at the point of care

- Acts as resource and support for staff

- Vertical management

- Identifies staff educational needs 
Table 1.2

Differences Between Professional Nursing Roles and the Role of the Clinical Nurse Leader (continued)

Clinical Nurse Specialist

- APRN

- Works at the macro- or mesosystem

- Involved in creating evidence and implements EBP through policy development

- Involved in care delivery and planning for cohort of patients

- Designs, implements, and evaluates programs of care to enhance patient outcomes across systems of care

- Collaborates with interprofessional care teams throughout the meso/ macrosystem

Certified Nurse Practitioner

- APRN

- Trained in the process of diagnosing and treating medical conditions

- Utilizes medical model of diagnosing and treating within their scope of practice

- Autonomous independent practice under the licensure and professional credentials

Nurse Educator

- Generally works at the macrosystem level

- Responsible for orientation/ inservices

- Educates in a more structured classroom setting

- Provides education targeting competencies and overall learning needs of individual units or areas within an organization
- Advanced generalist

- Works at the microsystem level

- Responsible for utilization of evidence at the point of care

- Performs comprehensive assessment of the patient/family/ caregiver

- Responsible for the ongoing assessment and modification of the plan of care and microsystem

- Collaborates with the interprofessional team at the point of care

- Advanced generalist

- Educated to complete advancedlevel physical assessments beyond the level of the RN

- Follows RN scope of practice

- Authentic leader who does not function independently but under the direction of the facility and providers of care

- Works at the microsystem level

- Point-of-care educator to nurses/ staff/interprofessional teams

- Addresses individual employee educational needs

- May collaborate with the nurse educator in identification of educational needs and educational programs

EBP, evidence-based practice. 


\section{ELEVATOR SPEECH}

You may have been introduced to the elevator speech and had an assignment to create one during your schooling. If you did, be sure to pull it out of your files and practice it. If you have not developed one, do it now. It will be extremely important to be able to quickly articulate who you are and what you do for patients, staff, and the interprofessional team. If you are just beginning on your unit as a $\mathrm{CNL}$, the care team may be wondering what your role actually is and how you fit into the team. It will also be important if you are in a meeting with administrators to tell them exactly what you do in just a minute or two. An example of an elevator speech may be, "Hi, I'm Susie the CNL on 11 East. I am an advanced generalist registered nurse at the point of care, coordinating patients and families with all healthcare team members and their associated resources, in an effort to create a patent-centered, transdisciplinary team. These coordination activities increase patient satisfaction and practitioner collaboration, leading to positive patient outcomes. Additionally, they decrease facility-acquired infections, falls, pressure ulcers, and many other negative outcomes, thereby decreasing healthcare costs and once again, boosting patient and provider satisfaction as a whole." Be sure to practice your speech a few times so you can state it quickly, articulating the high points of what you do.

\section{Creating a Portfolio}

Nurses may be familiar with portfolios which were a requirement during their educational programs, as many colleges of nursing require them as a means of documenting completed educational competencies and skills. Portfolios, however, are not widely used by professional nurses. As you move forward in your career as a nursing leader, it is important for you to document your professional accomplishments in order to demonstrate experience and skill to administrators and peers. It is also important for you to keep track of your activities for relicensure and recertification purposes.

A portfolio should highlight what you have done in the past. For example, what leadership activities have you been involved with? What committees have you worked on and chaired? What continuing education have you attended or even developed and presented? Have you written any published works? Have you presented at conferences? What quality improvement activities have you worked on? Have you precepted or mentored new nurses or students? All of these accomplishments demonstrate activities that go above and beyond your normal daily activities and demonstrate as well professional 
Table 1.3

\section{Clinical Nurse Leader (CNL) Resources}

\section{CNL Resources}

AACN General CNL Site

AACN Education and Practice Site

AACN Competencies and

Curricular Expectations for the

Clinical Nurse Leader (includes the

White Paper)

AACN Career Services Site

CNL Career Resource Guide

AACN/CNC The Clinical Nurse

Leader "Why Hire a CNL" Brochure

AACN Clinical Nurse Leader Tool Kit

Clinical Nurse Leader Association

CNC "Discover the Valuable Impact of the Certified CNL"
https://www.aacnnursing.org/CNL

https://www.aacnnursing.org/CNL/

Education-Practice-Resources

https://www.aacnnursing.org/

Portals/42/AcademicNursing/

CurriculumGuidelines/CNL

-Competencies-October-2013.pdf

https://www.aacnnursing.org/

CNL-Certification/CNL-Career-Services

https://www.aacnnursing.org/Portals/42/

CNL/CNL-Resource-Guide.pdf

https://www.aacnnursing.org/Portals/42/

CNL/Evolving-Role-of-CNL.pdf

https://www.aacnnursing.org/

Education-Resources/Tool-Kits/

Clinical-Nurse-Leader-Tool-Kit

https://cnlassociation.org/

http://discovercnls.org/

where-cnls-practice/

AACN, American Association of Colleges of Nursing; CNC, Commission on Nurse Certification.

growth and accountability. You may also want to maintain a listing of the outcomes you have contributed to in patient safety and outcomes that have contributed positively to the organization. Demonstrating your worth to the organization is instrumental for CNLs in sustaining their positions. Organizations evaluate positions and processes often when looking at their overall financial status. CNLs must demonstrate their value by keeping track of what they do and their overall benefit to the organization.

Think about how you currently keep track of what you do and how you can organize to maintain better records. It can be as easy as purchasing a three-ring binder with paper protectors. Place your continuing education certificates in the binder along with any thank you notes or recognition certificates. When working on projects, keep outlines of what the project is, the steps you have taken throughout the project, your contributions to the project, and especially the outcomes. These documents will be invaluable to you as you proceed in 
your career, demonstrating growth and potential to future employers and administrators.

\section{RESOURCES}

As you progress in your career as a CNL, keep in mind that there are resources to help you along the way. It is not always easy being a pioneer, but remember, you are a much needed discipline to patients and organizations. Your expertise, skills, and knowledge will improve practice, processes, and outcomes. The AACN (2018a) website has a section on career services, which will provide you with documents such as a resource guide and CNL talking points to help in compiling information to deliver the best speech ever. (See Table 1.3 for a complete listing.) The Clinical Nurse Leader Association is a professional organization for CNLs and CNL students that also offers resources and insight into what is happening in the CNL community. Stay connected with your classmates and peers who have gone on to positions in other organizations and attend conferences to get to know CNLs throughout the country. Be sure to network with as many CNLs as possible to help you achieve your dreams of changing healthcare for the better.

\section{References}

American Association of Colleges of Nursing. (2007). White paper on the education and role of the clinical nurse leader. Washington, DC: Author.

American Association of Colleges of Nursing. (2018a). CNL career services. Retrieved from https://www.aacnnursing.org/CNL-Certification/ CNL-Career-Services

American Association of Colleges of Nursing. (2018b). CNL certification. Retrieved from https://www.aacnnursing.org/CNL-Certification

Bender, M. (2014). The current evidence base for the clinical nurse leader: A narrative review of the literature. Journal of Professional Nursing, 30(2), 110-123. doi:10.1016/j.profnurs.2013.08.006

Case-Wirth, J. (2018, February). Hardwiring the CNL role into complex healthcare environments. Paper presented at the American Association of Colleges of Nursing, 2018 CNL. Summit, Garden Grove, CA.

Commission on Nurse Certification. (2017). A national snapshot of where CNLs practice. Retrieved from http://discovercnls.org/where-cnls-practice/

Hix, C., McKeon, L., \& Walters, S. (2009). Clinical nurse leader impact on clinical microsystems outcomes. The Journal of Nursing Administration, 39(2), 71-76. doi:10.1097/NNA.0b013e318195a612

Institute of Medicine. (1999). To err is human: Building a safer health system. Washington, DC: The National Academies Press.

Institute of Medicine. (2000). Crossing the quality chasm. A new health system for the 21st century. Washington, DC: The National Academies Press. 
Lahmiri, S. (2016). Economic decision-making, emotion, and prefrontal cortex. In B. Christiansen \& E. Lechman (Eds.), Neuroeconomics and the decision making process (pp. 122-131). Retrieved from https://ebookcentral -proquest-com.proxy.lib.ohio-state.edu

Makary, M., \& Daniel, M. (2016). Medical error-the third leading cause of death in the U.S. BMJ, 353, 1-5. doi:10.1136/bmj.i2139

Moore, P. (2013). The academic story: Introducing the clinical nurse leader role in a multifacility health care system. Journal of Professional Nursing, 29(5), 264-269. doi:10.1016/j.profnurs.2012.10.007

Ott, K., Haddock, K. S., Fox, S. E., Shinn, J. K., Walters, S. E., Hardin, J. W., ... Harris, J. L. (2009). The clinical nurse leader: Impact on practice outcomes in the Veterans Health Administration. Nursing Economics, 27(6), 363-383.

Ousdal, O., Specht, K., Server, A., Andreassen, O. A., Dolan, R. J., \& Jensen, J. (2014). The human amygdala encodes value and space during decision making. NeuroImage, 101, 712-719. doi:10.1016/j.neuroimage.2014.07.005

Rankin, V., Ralyea, T., \& Sotomayor, G. (2017). Clinical nurse leaders forging the path of population health. Journal of Professional Nursing, 34, 269-272. doi:10.1016/j.profnurs.2017.10.008

Sinek, S. (2009). Start with why. London, UK: Penguin Books.

Sinek, S. (2014). How great leaders inspire action [Video file]. Retrieved from https://www.ted.com/talks/simon_sinek_how_great_leaders_inspire _action?utm_campaign=tedspread\&utm_medium=referral\&utm_source =tedcomshare

Sotomayor, G., \& Rankin, V. (2017). Clinical nurse leaders: Fulfilling the promise of the role. MEDSURG Nursing, 26(1), 21-32.

Sternberg, S. (2016, May 3). Medical errors are third leading cause of death in the U.S. U.S. News \& World Report. Retrieved from https://www .usnews.com/news/articles/2016-05-03/medical-errors-are-third-leading -cause-of-death-in-the-us

U.S. Department of Veterans Affairs. (n.d.). Office of Nursing Services: Clinical Nurse Leader. Retrieved from https://www.va.gov/NURSING/practice/ cnl.asp 